Georgia State University

ScholarWorks @ Georgia State University

\title{
Common Core State Standards on Twitter: Public Sentiment and Opinion Leaders
}

Yinying Wang

Georgia State University, ywang103@gsu.edu

David J. Fikis

Follow this and additional works at: https://scholarworks.gsu.edu/eps_facpub

Part of the Education Commons, and the Education Policy Commons

\section{Recommended Citation}

Wang, Yinying and Fikis, David J., "Common Core State Standards on Twitter: Public Sentiment and Opinion Leaders" (2017). Educational Policy Studies Faculty Publications. 45.

https://scholarworks.gsu.edu/eps_facpub/45

This Article is brought to you for free and open access by the Department of Educational Policy Studies at ScholarWorks@ @eorgia State University. It has been accepted for inclusion in Educational Policy Studies Faculty Publications by an authorized administrator of ScholarWorks @ Georgia State University. For more information, please contact scholarworks@gsu.edu. 
Common Core State Standards on Twitter: Public Sentiment and Opinion Leaders

Yinying Wang*

Georgia State University

Yinying Wang is an assistant professor of educational leadership in the Department of Educational Policy Studies at College of Education and Human Development, Georgia State University. Her research interests include social network analysis in educational leadership and policy, social media in education policy making and organizational communication, and educational technology leadership.

David J. Fikis

Georgia State University

David J. Fikis is a doctoral candidate of research, measurement, and statistics in the Department of Educational Policy Studies at College of Education and Human Development, Georgia State University. His research focuses on score equating, psychometrics, item response theory, highperformance computing, and pedagogical advancements in quantitative methods instruction.

* Correspondence concerning this manuscript should be addressed to: Yinying Wang Georgia State University, 30 Pryor Street, Room 420, Atlanta, GA 30302-3977

Email: ywang103@gsu.edu 


\begin{abstract}
The purpose of this study is to examine the public opinion on the Common Core State Standards (CCSS) on Twitter. Using Twitter API, we collected the tweets containing the hashtags \#CommonCore and \#CCSS for 12 months from 2014 to 2015. A Common Core corpus was created by compiling all the collected 660,051 tweets. The results of sentiment analysis suggest Twitter users expressed overwhelmingly negative sentiment towards the CCSS in all 50 states. Five topic clusters were detected by cluster analysis of the hashtag co-occurrence network. We also found that most of the opinion leaders were those who expressed negative sentiment towards the CCSS on Twitter. This study for the first time demonstrates how text mining techniques can be applied to education policy research, laying the foundation for real-time analytics of public opinion on education policies, thereby informing policymaking and implementation.
\end{abstract}

Keywords: education policy, network analysis, network science, policymaking, politics, social media, sentiment analysis, text mining, the Common Core State Standards 
Common Core State Standards on Twitter: Public Sentiment and Opinion Leaders

\section{Introduction}

The purpose of this study is to examine the public opinion on the Common Core State Standards on Twitter. Since 2010, the adoption and implementation of the Common Core have stirred up much controversy (McDonnell \& Weatherford, 2013; Supovitz, Daly, \& Del Fresno, 2015). Many people willingly express their thoughts on the Common Core on social media, creating abundant geo-referenced, time-stamped data on the public opinion on the Common Core. Therefore, social media offers a unique proxy to advance our understanding of how the digital public perceive the Common Core and diffuse their perceptions that may shape others' perception of the Common Core. Mining public opinion expressed on social media, in particular with the applications of text mining analytical techniques in data acquisition, processing, and analysis, have been increasingly applied in the field of public policy to inform policymaking and implementation (Chung \& Zeng, 2015; Janssen, Wimmer, \& Deljoo, 2015; Reddicka, Chatfieldb \& Jaramilloa, 2015; Whitman, 2015). Yet in the field of educational policy, very limited studies have capitalized on social media data to examine public opinion on educational policies, let alone applying the emerging text mining techniques to inform policymaking and implementation. To fill the void, in this study we apply text mining techniques to examine the public opinion in the Common Core discourse on Twitter - a microblogging site that has been used by an increasing number of teachers (Carpenter \& Krutka, 2014), school principals and superintendents (Cho, 2016; Cox \& McLeoad, 2014a, 2014b; Wang, Sauers, \& Richardson, 2016), as well as educational institutions such as school districts (Wang, 2016a) and state education agencies (Wang, 2016b). To advance our understanding of the public opinion on the Common Core on Twitter, this study seeks to answers the following three research questions: 
- How did the public sentiment toward the Common Core State Standards vary, if any, across all states on Twitter?

- What was the topical structure in the Common Core discourse on Twitter?

- Who were the opinion leaders in the Common Core communication network on Twitter?

Given the widespread use of social media, the answers to these research questions shed light on how the Common Core unfolded on Twitter and how the Common Core adoption and implementation could be impacted by online public opinion. More importantly, this study lays the foundation for developing real-time analytics of public opinion on educational policies to overcome the time lag limitation from data collection to result report, thereby providing timely analytical results for evidence-based education policymaking and implementation.

\section{Literature Review}

This study draws from the literature on social media and policy research to illuminate how social media data can be capitalized on in the field of educational policy. In this section, we first present the background of the Common Core State Standards, followed by a review of the literature intersecting social media and public policy research. We next turn our attention to the conceptual framework grounded in network theory and ad hoc digital publics. Here I first provide a brief background of the Common Core State Standards.

\section{Background of the Common Core State Standards}

The Common Core State Standards, released in 2010, are the educational standards outlining the knowledge and skills that students in grades K-12 are expected to learn in English Language Arts (ELA) and mathematics (Common Core State Standards Initiative, 2016). To date, 43 states and the District of Columbia have adopted the Common Core. Among them, 23 
states have fully adopted the Common Core; 20 states have adopted with modification; one state (Minnesota) has partially adopted the standards (i.e., adopted only ELA standards but not mathematics standards) (Academic Benchmarks, 2016).

The sweeping adoption of the Common Core in its early stage was largely driven by bipartisan consensus and the far-reaching impact of the supporters with diverse organized interests (McDonnell \& Weatherford, 2013; Zernike, 2015). The supporters include the Common Core developers (e.g., the Council of Chief State School Officers and the National Governors Association), policy entrepreneurs (e.g., former North Carolina Governor James Hunt and former West Virginia Governor Robert Wise) who "promote a position in return for anticipated future gain in the form of material, purposive, or solidary benefits" (Kingdon, 1995, p. 179), national associations (e.g., the National Education Association, the American Federation of Teachers, and the National Parent Teacher Association), state-level organizations (e.g., the Chamber of Commerce and the California Office to Reform Education), foundations (e.g., the Bill and Melinda Gates Foundation and the GE Foundation), and private providers (e.g., the Pearson Education and the Student Achievement Partners).

Despite the supporters' diverse organized interests, the Common Core adoption and implementation have met with mounting resistance (McDonnell \& Weatherford, 2013; Polikoff, Hardaway, Marsh, \& Plank, 2016; Porter, Fusarelli, \& Fusarelli, 2014). Some argued that the federal incentivizing efforts — such as the Race to the Top grants and the No Child Left Behind waivers (Wohlstetter, Houston, \& Buck, 2014)—are the "federal coercions masquerading as inducements" (National Conference of State Legislatures, 2009, p. 22), intruding and threatening state autonomy (McDonnell \& Weatherford, 2013). Then the Every Student Succeeds Act of 2015 explicitly prohibits the federal government from the Common Core coercion (ESSA, 2015). 
Others raged about the insufficient evidence suggesting the national standards produce better educational outcomes, the unknown costs of the Common Core implementation, the lack of public debate before the adoption, the increased testing burden, and the foundations' role in the Common Core (McCluskey, 2010; Ujifusa, 2013; Rogers, 2015; Wallsten \& Layton, 2013). The opposition gained momentum among teacher-oriented bloggers, think tanks (e.g., the Cato Institute and the Pioneer Institute), state-based groups (e.g., the Hoosiers Against Common Core and the Tennessee Eagle Forum), Tea Party affiliates, and the Republican National Committee (McDonnell \& Weatherford, 2013). Nevertheless, at the early stage of Common Core implementation, McDonnell and Weatherford (2013) argued that the opposition to the Common Core, albeit confined to a limited number of states, in particular those with the Republicanmajority legislatures, "complicates and politicizes the already challenging task of implementing the Common Core, and it could gain momentum in some 2014 gubernatorial elections, especially in Republican primaries” (p. 495). In 2014, three states (South Caroline, Indiana, and Oklahoma) withdrew from the Common Core (Academic Benchmarks, 2016).

As the presidential campaign unfolded in 2015, joining the Republican presidential candidates who have always opposed the Common Core (e.g., Ben Carson, Ted Cruz, Rand Paul, and Donald Trump), other candidates (e.g., Jeb Bush, Chris Christie, Carly Fiorina, and Mike Huckabee) reversed their position from in favor of to opposing the Common Core (Catanese, 2015; Elkind, 2016). Moving beyond the political realm, educators have been grappling with the Common Core implementation in classrooms due to the lack of instructional support and the uncertainty of the Common Core brought by state legislation changes (Porter, Fusarelli, \& Fusarelli, 2014). This is consistent with the 2015 EdNext Poll on school reform among a nationally representative sample of 4,083 teachers and general public, in which the percentage of 
teachers opposing the Common Core quadrupled from $12 \%$ in 2013 to $50 \%$ in 2015; the percentage of general public opposing the Common Core almost tripled from $13 \%$ in 2013 to 35\% in 2015 (Henderson, Peterson, \& West, 2016).

The controversy and the mounting opposition to the Common Core merit particular attention to the evolving public opinion on the Common Core. Given the widespread use of social media by the public, to understand the public opinion expressed by social media users, we now turn our attention to the literature where social media and public policy research converge.

\section{Social Media and Policy Research}

Social media is defined as the online platforms that allow the creation, access, and exchange of user-generated content (Kaplan \& Haenlein, 2010). The emergence of social media has provided Internet users with a readily accessible platform to express and share their thoughts on any topic. Twitter, one of the most popular social media platforms, has some unique features that distinguish itself from other social media platforms. First, Twitter is a primarily open platform. Over $91 \%$ of Twitter users choose to make their Twitter profiles and communications visible to other Twitter users (Mislove, Lehmann, Ahn, Onnela, \& Rosenquist, 2012). Second, Twitter enables its users to post messages (also called tweets) of up to 140 characters about any topic. The 140-character limit, in fact, speeds up information diffusion, because unlike writing a blog post, crafting a tweet entails much lower investment in time and efforts (Demirbas, Bayir, Akcora, Yilmaz, \& Ferhatosmanoglu, 2010; Park, 2013). Third, using a hashtag, a word or phrase preceded by the \# symbol, people can readily identify the tweets containing the same hashtag. As a result, the Twitter's features of openness, brevity, and immediacy (Carpenter \& Krutka, 2014; Williams, Terras, \& Warwick, 2013) have rendered Twitter as a "platform most amenable to ongoing, public dialogue" (Junco, Heiberger, \& Loken, 2011, p. 1). 
To date, user-generated Twitter data have been considered as real-time "social sensors" of public opinion (Crooks, Croitoru, Stefanidis, \& Radzikowski, 2013; Preethi \& Ajit kumar, 2015; Siqi, Lin, Jehan, \& Venue, 2011; Weiler, Grossniklaus, \& Scholl, 2015). Twitter data usually offer rich details on human behaviors and contextual factors in policy research, including textual information (e.g., the text message on a given policy), temporal information (e.g., the time at which the message is posted), and communication information (e.g., who talks with whom about the policy) (Chung \& Zeng, 2015; Prpić, Taeihagh, \& Melton, 2015). As such, social media data have already been used to gauge public opinion on an array of public policies, including, but not limited to, the U.S. immigration policy and border security (Chung \& Zeng, 2015), space policy (Whitman, 2015), National Security Agency’s surveillance programs (Reddicka, Chatfieldb, \& Jaramilloa, 2015), climate change (Kirilenko \& Stepchenkova, 2014), healthy food (Widener \& Li, 2014), measles vaccination (Radzikowski, Stefanidis, Jacobsen, Croitoru, Crooks, \& Delamater, 2016), to name a few. The value of social media data in public policy research suggests educational policy research could potentially reap benefits from social media data as well.

The discourse on Twitter serves as the proxy to gauge and examine the public opinion on the Common Core on Twitter. While education policymakers' decision making is influenced by an array of factors (e.g., interest groups, political parties, and mass media), the policymakerswho are mostly publicly elected officials - still have the incentives to address and respond to public opinion in order to serve their constituents (Burstein, 2003; Gormley Jr., 2016; Page \& Shapiro, 1983). Given the fact that public opinion on educational policy can, at least to some extent, shape policymakers' decision making, researchers have studied public opinion on a variety of education issues, such as the policy in early childhood education (Gormley Jr., 2016), 
school reform (Henderson, Peterson, \& West, 2016), school quality (Jacobsen, Snyder, \& Saultz, 2014), and race-based and wealth-based student achievement gaps (Valant \& Newark, 2016), among others. Prior studies on public opinion on education and educational policy primarily used the data collected from surveys. However, in the case of Common Core, when Twitter is used as one of many communication platforms, the public opinion shared on Twitter contribute to the overall public opinion on the Common Core. In the digital era, with many Twitter users participating in the Common Core discourse by posting tweets containing the hashtags \#CommonCore and \#CCSS, those geo-referenced, time-stamped data enable us to trace, observe, and examine the Common Core discourse on Twitter, thereby advancing our understanding of the public opinion on the Common Core.

In education, the existing studies on Twitter primarily focus on why and how educators and organizations use Twitter. For instance, students, parents, teachers, and school leaders use social media to communicate with one another and build online communities (Carpenter \& Krutka, 2014; Cho, 2016; Cho, Ro, \& Littenberg-Tobias, 2013; Wang et al., 2016). Schools, districts, state education agencies, and the U.S. Department of Education also use social media to communicate with stakeholders and the digital public (Cox \& McLeod, 2014a, 2014b; Wang, 2016a). However, the intellectual efforts in using Twitter data, generated by millions of Twitter users, for educational policy research has been conspicuously absent. Supovitz and his team might be the first group of scholars who have ventured into the intersection of social media and educational policy, arguing that social media-enabled debate on educational policy incubates policy ideas and allows public opinion to emerge (Supovitz et al., 2015). In their study of the 189,658 tweets with the hashtag \#CommonCore posted between September 1, 2013 and March 4, 2014, Supovitz et al. (2015) identified three types of elite actors on Twitter (i.e., those who 
posted large number of tweets, those whose tweets were frequently retweeted, and those who were mentioned frequently and extensively by others), and then manually coded a random sample of 4,500 tweets posted by the elite actors as informational or opinion-based tweets. Supovitz et al.'s study, albeit valuable, did not address the challenge that the large volume and never-ending stream of social media data might render manual coding text data appallingly labor-intensive, time-consuming, and potentially impractical. Thus, this study extends Supovitz et al.'s (2015) line of research by applying the scalable text mining techniques from the emerging field of text mining to mine public opinion and identify opinion leaders on Twitter.

\section{Conceptual Framework}

This study is grounded in the network theory and the concept that hashtags help form ad hoc publics. In this section, we first explicate the network theory to provide a theoretical and analytical grounding for this study. We then delineate why and how a Twitter hashtag can be used to identify ad hoc publics to shed light on the public opinion toward a particular educational policy on Twitter.

\section{Network Theory}

A network consists of nodes and ties that connecting a pair of nodes (Borgatti, Everett, \& Johnson, 2013; Newman, 2013; Wasserman \& Faust, 1994). For example, a railway network is constituted of railway stations as nodes and railways as ties connecting the stations (e.g., Sen, Dasgupta, Chatterjee, Sreeram, Mukherjee, \& Manna, 2002); a journal citation network is constituted of journals as nodes and citations as ties that connecting the journals (e.g., Wang \& Bowers, 2016); a social network is constituted of people as nodes and social relationships as ties (e.g., Padgett \& Ansell, 1993); a political blog network is constituted of blogs as nodes and the hyperlinks connecting one blog to another as the ties (e.g., Adamic \& Glance, 2004). 
The network theory posits that the ties have a unique role in a network, as they serve as the conduit for resource exchange between the nodes (Borgatti \& Halgin, 2011; Burt, 2005; Degenne \& Forse, 1999; Granovetter, 1973; Wasserman \& Faust, 1994). Therefore, the presence and absence of ties, along with tie strength, facilitates or impedes resource exchange in the networks. In journal citation networks, the citation ties function as the conduit of knowledge exchange between journals (e.g., Leydesdorff, 2007; Wang \& Bowers, 2016). In policymaking networks, the cash and in-kind contribution ties function as the conduit of financial prowess on policymakers (Au \& Ferrare, 2014). As a corollary, the unique role of ties grants the nodes power and influence in the network: the nodes at the center of the network have more power and influence than those at the periphery of the network (Borgatti, 2005; Burt, 1999; Lin, 2009). In policymaking networks, those who are at the center are considered as influential policy actors. For instance, government actors were more influential than non-government actors in eight states' reading policymaking networks (Song \& Miskel, 2005); wealthy individuals, either directly through individual donations or indirectly through their affiliated philanthropic organizations, were far more influential than average voters in the charter school policymaking network (Au \& Ferrare, 2014); credential providers, market suppliers, legislative supporters, and public discourse disseminators are more influential than others in shaping teacher training policies (Kretchmar, Sondel, \& Ferrare, 2016). These influential policy actors - the nodes at the center of the networks - are also considered as opinion leaders, because they exert their influence by shaping others' opinion through dense incoming and outgoing ties in the networks. By contrast, the peripheral actors - those who are at the periphery of the network - engage in less communication, thereby having limited communication ties that function as the conduit spreading their opinion. By such logic, opinion leaders can be identified by examining whether 
individuals are at the center of a communication network (Rogers, 2003). In this study, the opinion leaders of the Common Core discourse on Twitter are those who position themselves at the center of the Common Core communication network via extensive and frequent communication ties.

\section{Hashtags Help Form Ad Hoc Publics}

How to identify online publics on a given topic on Twitter? Prior studies indicate that a hashtag - a user-defined word or phrase preceded by the \# symbol to identify a topic and tag a tweet (Messina, 2007) — can be used by Twitter users to form ad hoc publics around a particular topic (Bruns \& Burgess, 2011). The ad hoc publics can arise in response to emergencies or crises, such as \#BlackLivesMatter for the acquittal of George Zimmerman who fatally shot Trayvon Martin (Stephen, 2015), and \#BringBackOurGirls for the global campaign of bringing back the 276 girls abducted in Nigeria (Olson, 2016). The ad hoc publics can also be formed purposely via the hashtags that are deliberately chosen and used by organizations to engage the public. For example, many state education agencies use their state-relevant hashtags consistently, including \#vted (education in Vermont), \#ohioed (education in Ohio), and \#uted (education in Utah) (Wang, 2016b).

Some education researchers have already used hashtags to identify ad hoc publics. For instance, Davis (2015) interviewed 19 school teachers who participated in the weekly conversation about education on Twitter by using the hashtag \#EdChat (education-related chat on Twitter), and found that educators perceived Twitter as an instrumental platform to reflect upon teaching practices, as well as exchange knowledge and experience among supportive colleagues. Brewer and Wallis (2015) examined the tweets containing the hashtag \#TFA (Teach For America, the non-profit organization that recruits and places non-certified teachers in 
traditionally difficult-to-staff schools and districts), and found that TFA used Twitter to reinforce its reform rhetoric within its own reform coalition (e.g., Chief Executive Officers of charter networks, current TFA Corps members, and current TFA staff), but ignored critiques and counter-narratives. Yuen \& Pickering (2015) investigated 59,270 tweets containing the hashtag \#STEM (the science, technology, engineering, and mathematics education community), and found that neither STEM teachers nor university faculty members were the opinion leaders of the STEM education on Twitter. Fikis and Wang (2015) examined over one million tweets containing the hashtag \#EdPolicy (educational policy), and found that the opinion leaders on educational policy on Twitter were politicians, mass media, bloggers, and non-profit organizations. Consistent with the finding in Yuen and Pickering' (2015) study, Fikis and Wang (2015) also found that teachers, the main players in education, were not at the center of the \#EdPolicy communication network on Twitter.

In line with the literature on hashtags helping form ad hoc publics, this study uses two frequently used hashtags on the Common Core- \#CommonCore and \#CCSS (Fikis \& Wang, 2015; Supovitz et al., 2015; Wang, 2016b)_to identify the ad hoc publics on Twitter, examine their shared opinion, and identify opinion leaders. In the following section, we present in detail the procedures and methods used to mine public opinion and identify opinion leaders in the Common Core discourse on Twitter.

\section{Methods}

To examine the public opinion on the Common Core State Standards on Twitter, we used Twitter REST Application Program Interface (API) to collect the tweets containing the hashtags of \#CommonCore and \#CCSS. Using Twitter API, we collected a total of 660,051 tweets, along with the metadata on when the tweets were posted and their geolocations. All of the 660,051 
tweets containing the hashtags \#CommonCore and \#CCSS make up the Common Core corpus for data analyses that unfold in three parts. First, sentiment analysis was performed to gauge the emotions (positive, negative, or neutral) in each tweet. Then, cluster analysis of the hashtag cooccurrence network was performed to detect the topical structure in the corpus. Lastly, the communication network analysis was performed to identify opinion leaders of the Common Core discourse on Twitter. An overview of the research design in this study is illustrated in Figure 1.

Insert Figure 1 here

\section{Data Collection}

The hashtags of \#CommonCore and \#CCSS were chosen in this study to identify the tweets related to the Common Core discourse on Twitter. This is because recent studies suggest that both hashtags \#CommonCore and \#CCSS were frequently used on Twitter (Fikis \& Wang, 2015; Supovitz et al., 2015; Wang, 2016b). We thereby used Twitter API-the program that provides the public with efficient access to a random sample of approximately $1 \%$ of all realtime tweets (Murthy, 2013; Twitter, 2016) — to collect the tweets containing the hashtags of \#CommonCore and \#CCSS at a one-hour interval throughout each day from December 11, 2014 to December 14, 2015. All of the retrieved 660,051 tweets constitute the Common Core corpus. In comparison with Supovitz et al.'s (2015) Twitter dataset on the Common Core, the Common Core corpus in this study is unique in several ways. First, the timeframe of the tweets collected was extended from Supovitz et al.'s six months between September 1, 2013 and March 4, 2014 to 12 months between December 11, 2014 and December 14, 2015. Second, the data volume in this study's Common Core corpus $(660,051$ tweets) is three times as large as the 189,658 tweets 
in Supovitz et al.'s study. Third, both of the frequently used hashtags on the Common Core\#CommonCore and \#CCSS (Fikis \& Wang, 2015; Supovitz et al., 2015; Wang, 2016b)—were used in this study to identify the ad hoc publics on Twitter, whereas only \#CommonCore was included in Supovitz et al.'s study. In the current study's dataset of 660,051 tweets, the vast majority of the tweets $(83.23 \%)$ have the hashtag \#CommonCore, including $7.99 \%$ of the tweets have both hashtags \#CommonCore and \#CCSS. Yet there are $16.77 \%$ of the tweets containing the hashtag \#CCSS, but not \#CommonCore. As a result, this study's Common Core corpus, which comprises the tweets containing both \#CommonCore and \#CCSS, provides a more updated, inclusive picture of the Common Core discourse on Twitter.

\section{Geo-referencing}

A major task of preparing the Common Core corpus for analyses is geo-referencing. Among the 660,051 tweets, we found that $4,760(0.72 \%)$ tweets were geotagged. That is, when Twitter users choose to enable the geotagging feature, Twitter API provides the geoidentifier of latitude and longitude of the location where the tweets are posted. In the Common Core corpus of this study, the proportion of the geotagged tweets is consistent with approximately $1 \%$ of geotagged tweets reported in the Twitter studies in other fields (e.g., Jahanbakhsh \& Moon, 2014; Mislove et al., 2012; Ram, Zhang, Williams, \& Pengetnz, 2015; Young, Rivers, \& Lewis, 2014). In addition to the $0.72 \%$ of the geotagged tweets, Twitter API provides Twitter users' self-reported geographic locations in $73.0 \%$ of the tweets in the Common Core corpus. Again, the proportion of tweets with self-reported locations in this study is consistent with Mislove et al.’s (2012) study in which $75.3 \%$ of Twitter users self-reported locations in their Twitter profiles. We aimed to maximize the value of the data on self-reported geographic locations, and only meaningful geographic location data can be included to examine each state's collective 
sentiment towards the Common Core. In the Common Core corpus, some self-reported geographic locations (e.g., in the world, on your heart, and in the cloud) are not meaningful, we thereby excluded those tweets from sentiment analysis which aims to detect the sentiment disparities by state. Some Twitter users indicate multiple locations in their Twitter profiles, such as Georgia and Massachusetts. In this case, we created a category for multiple locations, and excluded the tweets associated with multiple locations from sentiment analysis as we could not geo-reference a particular tweet to a specific state. As a result, we were able to identify the meaningful geolocation of 264,038 (40.00\%) tweets in the Common Core corpus. Following the recommendation provided in other Twitter studies (Dai \& Hao, 2017), we then imputed the geographic locations by state. For instance, if a tweet's geolocation is Atlanta, Georgia, then we consider the geolocation of this tweet is Georgia. By doing so, we were able to perform sentiment analysis to gauge the digital public's sentiment towards the Common Core in each state.

\section{Sentiment Analysis}

Sentiment analysis, also known as opinion mining (Pang \& Lee, 2008), is the automatic computer-based analysis to detect sentiment expressed in a given text (Das \& Chen, 2007; Yi, Nasukawa, Bunescu, \& Niblack, 2003). Sentiment analysis is one of the fast-growing areas in the emerging field of text mining that uses computational modeling to analyze massive amounts of complex digital data, offering an alternative mode of inquiry for social scientists to enrich their understanding of social phenomena (Lazer et al., 2009; Shah, Cappella, \& Neuman, 2015; Watts, 2013). In this study, the sentiment of each of the 264,038 tweets with meaningful geolocations in the Common Core corpus was analyzed using SentiStrength. Among many sentiment analysis tools, SentiStrength was chosen because prior literature has consistently shown its high validity 
for tweet sentiment detection based on a lexicon-based method (Abbasi, Hassan, \& Dhar, 2014; Gonçalves, Araújo, Benevenuto, \& Cha, 2013; Lerman, Arora, Gallegos, Kumaraguru, \& Garcia, 2016; Lopes, Pinto, \& Francisco, 2016; Pfitzner, Garas, \& Schweitzer, 2012; Stieglitz \& Dangxuan, 2013; Witherspoon \& Stone, 2013). In particular, SentiStrength is considered to be by far one of the best unsupervised tool to analyze the sentiment expressed in tweets (Abbasi, Hassan, \& Dhar, 2014). Based on emotion-bearing words, SentiStrength categorizes each tweet into positive, neutral, and ngeative sentiment (see Thelwall, Buckley, Paltoglou, Cai, \& Kappas, 2010, for a thorough explication of the SentiStrength algorithm). Here we present some examples of tweet sentiment classification by using the tweets in the current study's dataset. The words that show positive or negative sentiment are in bold font followed by the signs "+" suggesting positive and "_" negative.

- Positive sentiment tweets

- Learn the essential strategies for achieving excellence [+] with the \#CommonCore. http://t.co/Yo8DhBcBj5

- I've always loved [+] these posters! \#ccss \#growthmindset \#education @ username \#cottonwoodpress

- Negative sentiment tweets

- We desperately [-] need a New Federal Education Initiative titled, "No Parent Left Behind" \#CommonCore sucks [-]

- Good [+] grief [-]! \#what if teachers didn't have to smuggle [-] reading into their reading programs? Stupid [-] \#CommonCore! \#tbats

- Neutral sentiment tweets 
- "If you don't know how you got there, you just have an answer on a piece of paper." Cicarellaon \#commoncore shift in problem solving

- Growth Mindset Made Visible \#edchat \#ccss \#commoncore https://t.co/QVqla9P5Mg

Using SentiStrength, we categorized each tweet into one of the three sentiments: positive, neutral, and negative. Then, the sentiment of each tweet was aggregated to the state level (i.e., the total number of positive, neutral, and negative sentiment tweets in each state), allowing us to examine the sentiment disparities by state. For each state, we calculated the Sentiment Index which we defined to be the ratio of the percentage of negative sentiment tweets in a given state to the percentage of positive sentiment tweets; thus:

$$
\text { Sentiment Index }=\frac{\text { the percentage of tweets with negative sentiment }}{\text { the percentage of tweets with positive sentiment }}
$$

The higher the Sentiment Index of a state has, the more negative sentiment towards the Common Core expressed in the tweets from the state. If the Sentiment Index is 1, then the state has the same percentage of positive and negative sentiment tweets.

\section{Hashtag Co-occurrence Network Analysis}

To detect the topical structure of the Common Core corpus, cluster analysis of the hashtag co-occurrence network was performed. As noted previously, hashtags are self-identified keywords of the tweets by Twitter users. Two hashtags share more similarity if they co-occur in a tweet than the similarity between two randomly chosen hashtags (Poschko, 2011). Moreover, the patterns of hashtag co-occurrences shed light on the topical structure on Twitter (Bode, Hanna, Yang, \& Shah, 2014). In this study we thus considered the hashtags in the corpus as the proxy for the topics related to the Common Core. In doing so, we created a hashtag cooccurrence network in which the hashtags were represented as nodes, and the co-occurrences of two hashtags were represented as ties. For instance, four hashtags (\#CommonCore, \#gagov, 
\#StopCommonCore, and \#gagop) co-occurred in a tweet "Jeremy Spencer talking about the coming storm Nathan Deal will face with \#CommonCore \#gagov \#StopCommonCore \#gagop http://t.co/oyM0WIBBsw", then there were six co-occurrence ties connecting the four hashtags in the hashtag co-occurrence network: (1) CommonCore-gagov, (2) CommonCoreStopCommonCore, (3) CommonCore-gagop, (4) gagov-StopCommonCore; (5) gagovgagop; and (6) StopCommonCore-gagop. We wrote $R$ code to repeat this procedure for all 660,051 tweets in the Common Core corpus to build the hashtag co-occurrence network. We then ran the faction algorithm — one of the network clustering algorithms — to partition the network (de Amorim, Barthélemy, \& Ribeiro, 1992; Glover, 1989, 1990), thereby detecting the clusters of hashtags in the network. According to network science (Borgatti et al., 2013), the cooccurrence relationships between hashtags in the same cluster are closer than the ones in different clusters. Thus, the clusters of hashtags manifest the frequently co-occurred topics and their interconnections in the Common Core discourse on Twitter. Further, to ensure the robustness of network partitions, following the recommendations for cluster analysis, we ran the faction algorithm multiple times with different initial partitions by using different random number seeds (Borgatti et al., 2013). If the same subgroups always emerged, then the network partition is considered robust. Therefore, in this study we examined the subgroups that are consistently detected by using the faction algorithm.

\section{Communication Network Analysis}

To identify the opinion leaders in the Common Core discourse on Twitter, five centralities - Indegree, Outdegree, In-Bonacich Power, Out-Bonacich Power, and betweenness degree-were calculated as the indicators of each Twitter user's influence in the Twitter communication network. Opinion leaders, according to Rogers (2003), are those who occupy the 
central structural locations in the communication network. In this study, the opinion leaders were those who have high centrality, calculated by performing social network analysis, in the communication network in which the Twitter users mention and/or reply to others by using $@$ username in tweets. To that end, this study focused squarely on the communication network by distinguishing communication networks from retweet networks. In the Common Core communication network, Twitter users are nodes and mentions and/or replies are ties; whereas in the retweet network, Twitter users are nodes and retweets are ties. This study defined the communication ties as the ones that connected two Twitter users when a Twitter user mentioned and/or replied to another Twitter user in the tweets. As such, if a Twitter user who tweeted frequently but nobody mentioned or replied, then this Twitter user was not included in the Common Core communication network. If a Twitter user sent out retweets, then the retweets were not considered as communication, as prior literature suggests mentions and/or replies indicate two-way communication whereas retweets are considered as one-way information broadcasting (Wang, 2016b). As a result, to identify opinion leaders in the communication network on the Common Core, we thus used 143,420 tweets in which a given Twitter user was mentioned and/or replied to in order to build the communication network. As a result, in the communication network, each node represents one of 52,910 unique Twitter users; each of 121,180 communication ties connects a pair of Twitter users when they mentioned or replied to each other in the tweets containing the hashtags \#CommonCore and \#CCSS.

All five centrality measures are the indicators of Twitter users' influence in the communication network, but each centrality conceptualizes influence in a unique way (Bonacich, 1987; Freeman, 1979). A Twitter user A's Indegree suggests how many other Twitter users mention A in tweets; Outdegree suggests how many Twitter users are mentioned by A (Freeman, 
1979). Moreover, this study calculated Bonacich power (Bonacich, 1987) — a centrality measure that takes into account not only a Twitter user's direct communication with other Twitter users (like Indegree and Outdegree), but also those Twitter users' communication with others. Therefore, In-Bonacich power suggests the potential influence of a Twitter user can have on others regarding the incoming communication; Out-Bonacich power suggests the potential influence of a Twitter user can have on others regarding the outgoing communication. Further, betweenness centrality (Freeman, 1979) is used to examine the extent of each Twitter user's role of being the information broker in the Common Core discourse on Twitter.

Taken together, using the Common Core corpus of over half of a million tweets, we conducted sentiment analysis to examine public sentiment towards the Common Core in each state. Cluster analysis of the hashtag co-occurrence network analysis was conducted to uncover the topical structure. Communication network analysis was conducted to identify opinion leaders in the Common Core discourse on Twitter.

\section{Results}

As noted previously, a total of 660,051 tweets constitute the Common Core corpus in this study. Figure 2 illustrates the volume of the tweets containing the hashtags \#CommonCore and \#CCSS by month. The largest volume of tweets in this study was collected in April 2015, suggesting that the peak time of the Common Core discourse on Twitter was probably driven by the testing season across the states. Mobile devices were the popular sources of tweets in the Common Core corpus. Specifically, $20.09 \%$ of tweets were posted from iPhones, followed by Android phones (13.72\%) and iPads (6.74\%). Collectively, mobile devices contributed as the sources for $40.55 \%$ of tweets in the corpus. In addition, approximately one-third (32.09\%) of 
tweets in the corpus were posted directly on the Twitter website, instead of the Twitter app on mobile devices.

\section{Overwhelmingly Negative Sentiment towards the Common Core on Twitter}

The results of sentiment analysis are quite striking. The Sentiment Indexes indicate that the negative sentiment towards the Common Core surpass the positive sentiment in all states and the District of Columbia. As noted in the Methods section, the higher the Sentiment Index of a state has, the more negative sentiment towards the Common Core expressed in the tweets from the state. Visualized in Figure 3, the states with a darker shade of color have more negative sentiment towards the Common Core. Virginia has the highest Sentiment Index (33.27) among all states, indicating that for every positive tweet on the Common Core, there were 33.27 negative tweets during the study period. One possible explanation is that the heated discussion on Twitter was sparked, as the House Bill 1752, the bill that prohibited the Board of Education from adopting the Common Core, passed the House and the Senate, but was vetoed by the Governor, and then the House and Senate overrode the Governor's veto in 2015 (Virginia's Legislative Information System, 2015). Washington has the lowest Sentiment Index at 1.00, indicating the almost same percentages of negative and positive sentimental tweets towards the Common Core in Washington state.

Is there any relationship between the states' Common Core Sentiment Index and the extent of Common Core adoption? Using the data on the Common Core adoption status in each state (Academic Benchmarks, 2016), we display in Table 1 the descriptive statistics of the Sentiment Indexes by five categories of the Common Core adoption across all states (adopted verbatim, adopted with modification, partially adopted, withdrawn, and not adopted). The correlation result indicates a significant relationship between the Sentiment Indexes of the 
verbatim-adoption states and the modified-adoption states, $r(41)=0.389, p=0.010$. This finding suggests that the Common Core verbatim-adoption states had less negative sentiment towards the Common Core than the modified-adoption states. Put differently, the less negative sentiment towards the Common Core was more likely to be expressed by Twitter users in the states adopting the Common Core more fully.

\section{Pluralistic Topical Structure of the Common Core Discourse}

To detect the topical structure of the Common Core discourse on Twitter, we applied the faction algorithm to cluster the hashtags that co-occurred with \#CommonCore and/or \#CCSS into subgroups based on their co-occurrence relationships in the hashtag co-occurrence network. The entire network contains 846 hashtags and 19,650 co-occurrence ties. Following Borgatti et al.'s (2013) recommendation on reducing the large network to a reasonable size for analysis and visualization, we focused on the pairs of hashtags that co-occurred at least 200 times in the Common Core corpus (i.e., the co-occurrence tie strength $\geq 200$ ). The network was then visualized in Figure 4, which contains 66 hashtags and 249 co-occurrence ties (tie strength $\geq$ 200).

Five clusters of hashtags thus emerged after applying the faction algorithm. The hashtags in the same cluster are coded by the same color (see Figure 4). A close examination of the hashtags within each cluster reveals the topical structure of the Common Core discourse on Twitter. The largest cluster (red, left) contains 21 hashtags, dominated by the hashtags about the 2016 presidential candidates affiliated with the Republican Party_-such as \#tedcruz, \#cruzcrew, \#tedcruz2016, \#jebbush, and \#trump2016. The hashtags in this cluster also show much negative sentiment towards the Common Core, including \#stopcommoncore, \#stopcc, and \#stopecaa (stop the Every Child Achieves Act). The second cluster (green, lower right) contains 17 hashtags, 
mostly revolving around Twitter chats, such as \#edchat, \#engchat, \#elachat (English language arts chat), \#mathchat, \#sschat (social studies chat), \#ntchat (new teacher chat), \#elemchat (elementary education chat), and \#ptchat (parent and teacher chat). The hashtags related to student assessments are also present in this cluster, including \#parcc (the Partnership for Assessment of Readiness for College and Careers) and \#sbac (the Smarter Balanced Assessment Consortium). The third cluster (black, right) is about educational policy and reform, such as \#edpolicy, \#edreform, \#nclb, \#esea, \#congress, and \#assessment. The fourth cluster (pink, upper right) is about teaching and testing, such as \#teachers, \#teaching, \#testing, \#education, and \#publicschools. Lastly, the hashtags in the fifth cluster (gray, upper left) do not demonstrate a consistent theme: some hashtags are related to different political ideologies, such as \#democrat, \#republican, \#teaparty, and \#tlot (Top Libertarians on Twitter); however, the hashtags in this cluster are not dominated by one particular political party.

\section{Opinion leaders Expressed Mostly Negative Sentiment towards the Common Core}

Thus far, we found overwhelmingly negative sentiment towards the Common Core in all states and a pluralistic topical structure of the Common Core corpus. These findings beg the question: Who were the opinion leaders having a relatively large influence in the Common Core communication network on Twitter? Given the fact that most states have adopted the Common Core, was it possible that parents and teachers expressed widespread negativity across the states, but the policymakers and those who advocated for the Common Core were the opinion leaders with positive sentiment? Or was it possible that the opposition to the Common Core has gained momentum "in some 2014 gubernatorial elections, especially in Republican primaries" (p. 495), as predicted by McDonnell and Weatherford (2013)? 
To answer these questions, we used five centrality measures to identify the opinion leaders in the communication network made of 52,910 unique Twitter users and 121,180 communication (mention and/or reply) ties. On the one hand, a vast majority $(86,123,71.07 \%)$ of the communication ties have tie strength at one, indicating most Twitter users communicate with one another only once regarding the Common Core. On the other hand, $366(0.30 \%)$ Twitter users communicated with one another at least 30 times. The identity of the high-centrality Twitter users - those who are at the center of the Common Core communication network-is not divulged for privacy consideration; therefore, Table 2 displays the de-identified results of the high-centrality Twitter users and their sentiment towards the Common Core. As seen in Table 2, the high-centrality Twitter users' sentiment is color coded: the gray cell represents that the Twitter user who expressed negative sentiment towards the Common Core; the white cell represents neutral sentiment. A Twitter user's sentiment towards the Common Core was detected through multiple approaches: (1) the sentiment expressed on a particular Twitter user's Twitter profile, such as using the hashtag \#StopCC or the words "No Common Core"; (2) the sentiment expressed by the tweets posted by a particular Twitter user; and (3) the sentiment expressed by the tweets mentioned and/or replied to a particular Twitter user. Among the 34 high-centrality Twitter users, none expressed positive sentiment towards the Common Core; only one (User11) expressed neutral sentiment. The rest of 33 high-centrality Twitter users expressed negative sentiment towards the Common Core (e.g., User9 and User12 are the Twitter accounts for a group of teachers, respectively; User32 is the Twitter account for a group of parents). Regarding the political party affiliations of the high-centrality Twitter users, the absence of the Democratic Party was conspicuous: none of the Twitter users in Table 2 was affiliated with the Democratic Party, at least according to the users' Twitter profile. By sharp contrast, many of the high- 
centrality Twitter users were affiliated with the Republican Party: User4 and User24 were the presidential candidates; User2, User5, User6, User19, User28, and User29 identified themselves as Republicans in their Twitter profiles.

\section{Discussion}

This study might be the first one in the field of educational policy that applied sentiment analysis and network analysis to examine the public opinion on the Common Core expressed in over half a million tweets containing the hashtags \#CommonCore and \#CCSS. We found that the negative sentiment towards the Common Core surpassed the positive sentiment in all states. We detected a pluralistic topical structure of the Common Core discourse, including five tight-knit hashtag clusters (politics and anti-Common Core, educators' weekly Twitter chats and assessment, educational policy and reform, teaching and testing, and non-specific). We also found most of the opinion leaders expressed negative sentiment towards the Common Core (e.g., the Twitter accounts for two groups of teachers and a group of parents), as well as those who were affiliated with the Republican Party (e.g., presidential candidates and their supporters). Our findings shed light on the emerging intersection of educational policy, politics, and social media. In the remainder of this article, we discuss the role of social media and politics in the Common Core discourse, followed by the methodological implications of this study. This paper concludes with the limitations and suggestions for future inquiry.

\section{The Role of Social Media in the Common Core Discourse}

This study draws attention to an important, though underexplored, line of inquiry on the impact of social media on educational policy. The results of this study will guide further inquiry into the role of social media in shaping online public opinion on educational policies. We found the widespread negativity towards the Common Core from Twitter users in all states. However, 
with the dataset in this study, we did not have sufficient evidence to conclude whether the policymakers were responding to their constituents on the issues related to the Common Core. Nevertheless, does the Common Core discourse on Twitter resemble an echo chamber-an environment in which individuals primarily exchange information with those with similar ideological preferences (Adamic \& Glance, 2005; Iyengar \& Hahn, 2009), as identified in the Twitter discourse on the 2012 presidential election, the 2013 government shutdown, and the 2014 State of Union address (Barberá, Jost, Nagler, Tucker, \& Bonneau, 2015)? The findings in this study suggest an affirmative answer. Specifically, the findings suggest an echo chamber dominated by negative sentiment towards the Common Core, as attested by the overwhelmingly negative sentiment across the states and the finding that 33 of 34 high-centrality Twitter users expressed negative sentiment. A recent study suggests that social media users' opinion on a controversial topic is influenced by their exposure to the one-sided social media comments, regardless of their reported level of previous knowledge (Witteman, Fagerlin, Exe, Trottier, \& Zikmund-Fisher, 2016). Granted, the echo chamber effect is not unique to the Common Core discourse on Twitter. Prior literature suggests that the Internet reinforces the echo chamber effect: the Internet is more effective in "preaching the converts" (Norris, 2003, p. 24) and mobilizing supporters than persuading and changing people's beliefs, attitudes, and opinions (Bimber \& Davis, 2003; Vaccari, 2012). It is thus important that we recognize the limited role of online communication platforms in policy debates drawing on "vox populi" (voice of people, if translated from Latin) (Galton, 1907, p. 450). In the case of the Common Core, the overwhelmingly negative sentiment is likely to amplify the echo chamber effect when the Common Core has already been framed as a government intrusion into children's lives, an opportunity for corporations to wring profits from public education, a battleground of culture 
wars, an experiment on children, and a means of brainwashing children (Supovitz \& Reinkordt, 2017).

Further, in comparison with other Twitter users discussing the Common Core, educators appear to use Twitter in a unique manner: educators participated in their weekly Twitter chatsas evidenced by the green hashtag cluster in Figure 4- to share and exchange ideas on teaching, learning, and student assessments (e.g., the Partnership for Assessment of Readiness for College and Careers and the Smarter Balanced Assessment Consortium). Moreover, two teacher groups' Twitter accounts emerged as the opinion leaders in the Common Core communication network on Twitter. By contrast, the lack of education research associations' and researchers' presence in the Common Core discourse on Twitter suggests that "the often muted voice of researchers in the policy process" (McDonnell, 2016, p. 147) applies to online environment as well. While "education research cannot depoliticize decisionmaking" (Shavelson, 1988, p. 6), education research contributes to policy "by helping to construct, by challenging, and by changing the way policymakers and practitioners view particular problems" (p. 4). The findings of this study raise new questions: How to inform the digital public on educational policy issues on social media? How to effectively disseminate valid, research-based evidence to inform education policymaking so that bodies of evidence do not lay inert in research journals? How to use social media to garner public support for the policies that aim to provide equitable education and create socially just learning environments for all students? To answer these questions, future inquiry is encouraged to venture into the intersection of educational policy, politics, public opinion, and social media. 


\section{The Changing Political Context of Common Core}

As "public education became more politicized" (McDonnell, 2016, p. 143), the Common Core discourse on Twitter, unsurprisingly, is politicized as well. The topics identified in this study were less about teaching and learning, even though the intention of the Common Core policy was for the interest of our students and the future of the United States. The statementspolicies shape politics (Schattschneider, 1935), and vice versa (McDonnell, 2009)—do not miss their relevance to the educational policies in the digital age, as the results of this study reveal a highly politicized context of the Common Core policy. In comparison with Supovitz et al.'s (2015) study that identified the presence of political discussion over the Common Core on Twitter from 2013 to 2014, this study went a step further and found that the traditional partisan dichotomy was not present in the Common Core discourse on Twitter from 2014 to 2015. Rather, the opinion leaders in the Common Core discourse were dominated by those imply a political ideology leaning toward the Right. This finding can be explained by the changing political context of the Common Core policy: the bipartisan consensus at the early stage of Common Core adoption met with mounting resistance as many Republicans, particularly the Republican presidential candidates, reversed their position from in favor of to opposing the Common Core (Elkind, 2016; McDonnell \& Weatherford, 2013; Zernike, 2015). If education policymaking, as Parkhurst (2017) argued, is inherently political and is more than technical decision making that centers around whether and how the adoption and implementation of the Common Core enhance student learning, then it wound be vain efforts to depoliticize the Common Core. The key is not to dismiss or exalt politically motivated tweets, but to "embracing the political nature of policymaking head-on" (Parkhurst, 2017, p. 8). To do so, we need to ask the questions: To what extent does rigorously, systematically evaluated evidence have a bearing 
on the Common Core policy? What constitutes legitimate evidence to inform the Common Core policy? How to ensure legitimate evidence is presented systematically instead of being cherrypicked? The data in this study did not provide the answers, and hopefully these questions would invite future researchers to untangle the close interplay between politics and education policymaking.

\section{Methodological Implications}

This study provides a proof of concept and an initial benchmark of how social media data can be used to detect online public opinion on educational policies. Sentiment analysis detects the sentiment expressed in tweets in an automated approach; cluster analysis of the hashtag cooccurrence network examines the topical structure from the perspective of co-occurrence ties between pairs of hashtags; social network analysis identifies the online opinion leaders at the center of the communication network on Twitter. Indeed, the Common Core corpus in this study can be analyzed through traditional qualitative and quantitative approaches. However, the data collected from social media are usually characterized by high volume (large amounts of data) and high velocity (high speed of data generation) (Watts, 2013). The high-volume and highvelocity social media data pose methodological challenges to analyze data in a timely manner. The alternative methodological approaches demonstrated in this study lay a promising foundation for real-time analytics, because the analytical techniques used in this study can be automated and scaled up, thereby presenting real-time results of online public opinion on educational policies. The hashtags used in this study (\#CommonCore and \#CCSS) can be replaced by any emerging hashtag on an educational policy. As a result, the methodological approaches employed in this study can be replicated in the studies of public opinion on any educational policy on Twitter. The traditional educational policy research methods usually lead 
to a time lag of months, if not years, between data collection and result report. This time lag imposes a severe limitation in education policymaking and implementation in a political environment where education problems and solutions are evolving constantly. Therefore, bringing in computational methods for social media data acquisition by using API, automated text mining, and social network analysis, this study presents the potential of overcoming the time constraint in traditional educational policy research, and provides policymakers with real-time results of online public opinion on education policies, thereby informing future education policymaking and implementation. While all three methodological approaches used in this study can be automated, it is important to note that they do not supplant conventional methodological approaches to analyze text data. Rather, the automated analytical approaches compliment the conventional approaches to analyze qualitative data (Grimmer \& Stewart, 2013; King, 2011, 2016). As Grimmer and Stewart (2013) noted, the automated analytical approaches do not replace humans, but "amplify human abilities" (p. 4). Together, they enhance the veracity of analytical results.

\section{Limitations and Suggestions for Future Inquiry}

The results of this study must be interpreted with caution due to several limitations. First, the results of correlation tests only suggest that the negative sentiment towards the Common Core was more likely to be expressed by Twitter users in the states adopted the Common Core more fully. However, we do not have sufficient evidence to claim the causality, because it is possible that the state's full adoption of Common Core caused less negative sentiment expressed of by Twitter users in the state, or it is possible the other way around. Given the findings in this study, future inquiry is recommended to investigate the relationship between public sentiment and Common Core implementation. Fine-grained data on Common Core implementation will 
enrich our understanding of the mechanism between how the Common Core is implemented and how the public and policymakers respond accordingly. Second, this study only includes approximately $1 \%$ of tweets, instead of all tweets, containing the hashtags \#CommonCore and \#CCSS. Twitter API provides a real-time random sample of $1 \%$ of all tweets posted by Twitter users; therefore, it is unknown whether the high-volume Twitter users - those who post a large number of tweets - are disproportionately favored by Twitter API. To that sense, the results of this study might not be generalized to all Twitter users or the entire population in the United State. Further, Twitter users represent only $23 \%$ of Internet users and demonstrate certain demographic features, including the underrepresentation of Hispanic Twitter users in the southwest and African-American Twitter users in the South and Midwest (Duggan, 2015; Mislove et al., 2013). We thus encourage future studies to examine the differences, if any, between the public opinion towards the Common Core on Twitter and the opinion expressed by the public representative of the entire population. Third, despite the public opinion detected on Twitter in this study, the 140-character limitation on each tweet might be too limited for an indepth discussion on the Common Core to take place on Twitter. Therefore, we encourage future researchers to delve into other sources of public opinion on the Common Core, including blogs, online discussion forums, and Facebook posts. Fourth, sentiment analysis in this study does not take into account the sentiment of the webpage text directed by the hyperlinks in tweets. Also, the fully automated sentiment analysis does not detect sarcasm very well. Sarcastic praises, instead of suggesting positive sentiment, actually carry negative sentiment (Altrabsheh, Cocea, \& Fallahkhair 2015). As the techniques of sentiment analysis continue to mature, we highly encourage future inquiry to include the sentiment expressed in the text on the webpages directed by the hyperlinks in tweets and the sentiment expressed through sarcasm. The fifth limitation 
derives from the variation in the geo-referencing accuracy between geotagged locations and selfreported locations in the Twitter user profile. In comparison, geotagged locations are more accurate, as they are based on each tweet, whereas self-reported geolocations are based on Twitter users who might move from state to state. If a Twitter user moves from Alabama to Wisconsin without changing the self-reported location in the Twitter user profile, it is unknown to us that the geographic location of the tweets from this particular user should be updated to Wisconsin. Therefore, future studies are recommended to develop new techniques to improve the accuracy of geo-referencing of social media data. Lastly, this study is a snapshot of public opinion on Common Core on Twitter. As the analytical methods of social media data continue to advance, we highly encourage future researchers to capitalize on the fine-grained, time-stamped, and geo-referenced social media data to develop real-time or near real-time analysis of public opinion on educational policies, to longitudinally track the change of public opinion, to examine how public opinion plays a role in the fluid political, societal, economic, and cultural ecosystem of education policymaking and implementation, as well as to inform policymakers in their evidence-based decision making process. 


\section{References}

Abbasi, A., Hassan, A., \& Dhar, M. (2014). Benchmarking Twitter sentiment analysis tools. Proceedings of the International Conference on Language Resources and Evaluation, Reykjavik, Iceland, 26-31 May (pp. 823-829). European Language Resources Association.

Academic Benchmarks. (2016). Common Core State Standards adoption map. Retrieved from http://academicbenchmarks.com/common-core-state-adoption-map/

Adamic, L. A., \& Glance, N. (2005). The political blogsphere and the 2004 U.S. election divided they blog. Proceedings of the Third International Workshop on Link discovery (p.36-43). doi: $10.1145 / 1134271.1134277$

Altrabsheh, N., Cocea, M., \& Fallahkhair, S. (2015). Detecting sarcasm from students' feedback in Twitter. In G. Conole, T. Klobučar, C. Rensing, J. Konert, \& É. Lavoué (Eds.), Design for teaching and learning in a networked world (pp. 551-555). Switzerland: Springer International Publishing.

Au, W., \& Ferrare, J. J. (2014). Sponsors of policy: A network analysis of wealthy elites, their affiliated philanthropies, and charter school reform in Washington State. Teachers College Record, 116, 080306.

Barberá, P., Jost, J. T., Nagler, J., Tucker, J. A., \& Bonneau, R. (2015). Tweeting from left to right: Is online political communication more than an echo chamber? Psychological Science, 26(10), 1531-1542.

Bimber, B., \& Davis, R. (2003). Campaigning online: The Internet in US elections. Oxford, New York: Oxford University Press. 
Bode, L., Hanna, A., Yang, J., \& Shah, D. (2014). Candidate networks, citizen clusters, and political expression: Strategic hashtag use in the 2010 Midterms. The Annals of the American Academy of Political and Social Science, 659(1), 149-165.

Bonacich, P. (1987). Power and centrality: A family of measures. American Journal of Sociology, 92, 1170-1182.

Borgatti, S. P. (2005). Centrality and network flow. Social Networks, 27, 55-71.

Borgatti, S. P. (2006). Identifying sets of key players in a network. Computational, Mathematical and Organizational Theory, 12(1), 21-34.

Borgatti, S. P., Everett, M. G., \& Johnson, J. C. (2013). Analyzing social networks. Thousand Oaks: Sage.

Borgatti, S. P., \& Halgin, D. S. (2011). On network theory. Organizational Science, 22(5), 11681181.

Brewer, T. J., \& Wallis, M. (2015). \#TFA The intersection of social media and education reform. Critical Education, 6(14), 1-17.

Bruns, A., \& Burgess, J. E. (2011, August). The use of Twitter hashtags in the formation of ad hoc publics. Paper presented at the 6th European Consortium for Political Research General Conference, University of Iceland, Reykjavik. Retrieved from http://bit.ly/1NE6ScQ

Burstein, P. (2003). The impact of public opinion on public policy: A review and an agenda. Political Research Quarterly, 56(1), 29-40.

Burt, R. S. (1999). The social capital of opinion leaders. The Annual of the American Academy of Political and Social Science, 566(1), 37-54. 
Burt, R. S. (2005). Brokerage and closure: An introduction to social capital. Oxford, UK: Oxford University Press.

Carpenter, J. P. \& Krutka, D. G. (2014). How and why educators use Twitter: A survey of the field. Journal of Research on Technology in Education, 46(4), 414-434.

Catanese, D. (2015, August 14). Bush: "Common Core” is “poisonous". U.S. News. Retrieved from http://www.usnews.com/news/blogs/run-2016/2015/08/14/jeb-bush-common-coreis-poisonous

Cho, V. (2016). Administrators' professional learning via Twitter: The dissonance between beliefs and actions. Journal of Educational Administration, 54(3), 340-356.

Cho, V., Ro, J., \& Littenberg-Tobias, J. (2013). What Twitter will and will not do: Theorizing about teachers' online professional communities. Learning Landscapes, $6(2), 45-62$.

Chung, W., \& Zeng, D. (2015). Social-media-based public policy informatics: Sentiment and network analyses of U.S. Immigration and border security. Journal of the Association for Information Science and Technology, 67(7), 1588-1606.

Cox, D., \& McLeod, S. (2014a). Social media marketing and communications strategies for school superintendents. Journal of Educational Administration, 52(6), 850-868.

Cox, D., \& McLeod, S. (2014b). Social media strategies for school principals. NASSP Bulletin, $98(1), 5-25$.

Crooks, A., Croitoru, A., Stefanidis, A., \& Radzikowski, J. (2013). \#Earthquake: Twitter as a distributed sensor system. Transactions in GIS, 17(1), 124-147.

Dai, H., \& Hao, J. (2017). Mining social media data for opinion polarities about electronic cigarettes. Tobacco Control, 26(2), 175-180. 
Das, S., \& Chen, M. (2007). Yahoo! For Amazon: Sentiment extraction from small talk on the web. Journal of Management Science, 53(9), 1375-1388.

Davis, K. (2015). Teachers' perceptions of Twitter for professional development. Disability \& Rehabilitation, 37(17), 1551-1558.

de Amorim. S. G., Barthélemy, J., \& Ribeiro, C. C. (1992). Clustering and clique partitioning: Simulated annealing and tabu search approaches. Journal of Classification, $9(1), 17-41$.

Degenne, A., \& Forse, M. (1999). Introducing social networks. London, UK: Sage.

Demirbas, M., Bayir, M. A., Akcora, C. G., Yilmaz, Y. S, \& Ferhatosmanoglu, H. (2010). Crowd-sourced sensing and collaboration using Twitter. Proceedings of 2010 IEEE International Symposium on a World of Wireless Mobile and Multimedia Networks. New York, NY: IEEE. doi: 10.1109/WOWMOM.2010.5534910

Duggan, M. (2015, August, 19). The demographics of social media users. Pew Research Center: Mobile Messaging and social Media. Retrieved from http://www.pewinternet.org/2015/08/19/the-demographics-of-social-media-users/

Elkind, P. (2016, January 1). Business gets schooled: How Exxon Mobile, GE \& others learned a hard lesson in the war over Common Core. Fortune. Retrieved from http://fortune.com/common-core-standards/

Every Student Succeeds Act (ESSA) of 2015, Public Law No. 114-95 §§ 8526A

Fikis, D., \& Wang, Y. (2015, November). Identifying opinion leaders and mining topics of the \#EdPolicy discourse on Twitter. Paper presented at the 2015 Annual Convention of University Council for Educational Administration. San Diego, CA. 
Freeman, L. C. (1979). Centrality in social networks: Conceptual clarification. Social Networks, $1,215-239$.

Galton, F. (1907). Vox Populi. Nature (March 7), 75, 450-451.

Glover, F. (1989). Tabu Search-Part I. ORSA Journal on Computing, 1(3), 190-206

Glover, F. (1990). Tabu Search-Part II. ORSA Journal on Computing 2(1), 4-32.

Gonçalves, P., Araújo, M., Benevenuto, F., \& Cha, M. (2013). Comparing and combing sentiment analysis methods. Proceedings of the first ACM Conference on Online Social Networks, Boston, MA, 7-8 October (pp. 27-38). New York, NY: The Association for Computing Machinery. doi: 10.1145/2512938.2512951

Gormley Jr., W. T. (2016). From science to policy in early childhood education. Science, 333(6045), 978-981.

Granovetter, M. S. (1973). The strength of weak ties. American Journal of Sociology, 78(6), 1360-1380.

Grimmer, J., \& Stewart, B. M. (2013). Text as data: The promise and pitfalls of automatic content analysis methods for political texts. Political Analysis, 21(3), 267-297.

Henderson, M. B., Peterson, P. E., \& West, M. R. (2016). The 2015 EdNext Poll on School Reform. EducationNext, 16(1). Retrieved from http://educationnext.org/2015-ednextpoll-school-reform-opt-out-common-core-unions/

Iyengar, S., \& Hahn, K. S. (2009). Red media, blue media: Evidence of ideological selectivity in media use. Journal of Communication, 59(1), 19-39.

Jacobsen, R., Snyder, J. W., \& Saultz, A. (2014). Informing or shaping public opinion? The influence of school accountability data format on public perceptions of school quality. American Journal of Education, 121(1), 1-27. 
Jahanbakhsh, K., \& Moon, Y. (2014). The predictive power of social media: On the predictability of U.S. Presidential Election using Twitter. arXiv:1407.0622. Retrieved from http://arxiv.org/pdf/1407.0622v1.pdf

Janssen, M., Wimmer, M. A., \& Deljoo A. (Eds.). (2015). Policy practice and digital science: Integrating complex systems, social simulation and public administration in policy research. Switzerland: Springer.

Junco, R., Heiberger, G., \& Loken, E. (2011). The effect of Twitter on college student engagement and grades. Journal of Computer Assisted Learning, 27(2), 119-132.

Kaplan, A. M., \& Haenlein, M. (2010). Users of the world, unite! The challenges and opportunities of social media. Business Horizons, 53(1):59-68.

King, G. (2011). Ensuring the data-rich future of the social sciences. Science, 331(6018), 719721.

King, G. (2016). Preface: Big data is not about the data. In R. M. Alvarez (Ed.), Computational Social Science: Discovery and Prediction (pp. vii-x). New York, NY: Cambridge University Press.

Kingdon, J. W. (1995). Agenda, alternatives, and public policies ( $2^{\text {nd }}$ ed.). New York, NY: HarperCollins.

Kirilenko, A. P., \& Stepchenkova, S. O. (2014). Public microblogging on climate change: One year of Twitter worldwide. Global Environmental Change, 26, 171-182.

Kretchmar, K., Sondel, B., \& Ferrare, J. J. (2016). The power of the network: Teach for America's impact on the deregulation of teacher education. Educational Policy, OlineFirst. doi: 10.1177/0895904816637687 
Lazer, D., Pentland, A., Adamic, L., Aral, S., Barabási, A., Brewer, D., ... Van Alstyne, M. (2009). Life in the network: The coming age of computational social science, Science, 323(5915), 721-723.

Lerman, K., Arora, M., Gallegos, L., Kumaraguru, P., \& Garcia, D. (2016). Emotions, demographics and sociability in Twitter. Retrieved from http://precog.iiitd.edu.in/Publications_files/Lerman_Arora_ICWSM_2016.pdf

Lin, N. (2009). Social capital: A theory of social structure and action ( $8^{\text {th }}$ ed.). New York, NY: Cambridge University Press.

Leydesdorff, L. (2007). Betweenness centrality' as an indicator of the 'interdisciplinarity' of scientific journals. Journals of the American Society for Information Science and Technology, 58(9), 1303-1309.

Lopes, H., Pinto, H. S., \& Francisco, A. P. (2016). Influence and sentiment homophily on Twitter social circles. In H. Cherifi, B. Goncalves, R. Menezes, \& R. Sinatra (Eds.), Complex Networks VII: Proceedings of the 7th Workshop on the Complex Networks CompleNet 2016 (pp. 349-361). Switzerland: Springer International Publishing.

McCluskey, N. (2010, February 17). Behind the curtain: Assessing the case for national curriculum standards (Policy Analysis No. 661). Washington, DC: Cato Institute.

McDonnell, L. M. (2009). Repositioning politics in education's circle of knowledge. Educational Researcher, 38(6), 417-427.

McDonnell, L. M. (2016). Evolving research perspectives on education politics and policy. Educational Researcher, 45(2), 142-148.

McDonnell, L. M., \& Weatherford, M. S. (2013). Organized interests and the Common Core. Educational Researcher, 42(9), 488-497. 
Messina, Chris. (2007, August, 25). Groups for Twitter; or a proposal for Twitter tag channels. FactoryCity. Retrieved from http://factoryjoe.com/blog/2007/08/25/groups-for-twitter-ora-proposal-for-twitter-tag-channels/

Mislove, A., Lehmann, S., Ahn, Y., Onnela, J., \& Rosenquist, J. N. (2012). Understanding the demographics of Twitter users. Association for the Advancement of Artificial Intelligence. Retrieved from http://www.ccs.neu.edu/home/amislove/publications/Twitter-ICWSM.pdf

Murthy, D. (2013). Twitter: Social communication in the Twitter age. Cambridge, UK: Polity. National Conference of State Legislatures. (2009). Education at a crossroads: A new path for federal and state education policy: Findings and recommendations of the NCSL Task Force on federal education policy. National Conference of State Legislatures Education Task Force, Denver, CO, and Washington, D.C. Retrieved form http://www.nmlegis.gov/lcs/lesc/lescdocs/briefs/June2010/Item\%207\%20-\%20David\%20 Shreve\%20of\%20NCSL\%20-\%20Education\%20at\%20a\%20Crossroads.pdf

Newman, M. E. J. (2013). Networks: An introduction. Oxford, UK: Oxford University Press. Norris, P. (2003). Preaching to the converted? Pluralism, participation and party websites. Party Politics, 9(1), 21-45.

Olson, C. C. (2016). \#BringBackOurGirls: Digital communities supporting real-world change and influencing mainstream media agendas. Feminist Media Studies, 14(6), http://www.tandfonline.com/eprint/aJX9ySjsJYd45iJkd5uZ/full

Padgett, J. F., \& Arsell, C. K. (1993). Robust action and the rise of the Medici, 1400-1434. American Journal of Sociology, 98(6), 1259-1319.

Page, B. I., \& Shapiro, R. Y. (1983). Effects of public opinion on policy. American Political Science Review, 77(1), 175-190. 
Pang, B., \& Lee, L. (2008). Opinion mining and sentiment analysis. Foundations and Trends in Information Retrieval, 2(1-2), 1-135.

Park, C. (2013). Does Twitter motivate involvement in politics? Tweeting, opinion leadership, and political engagement. Computers in Human Behavior, 29(4), 1641-1648.

Parkhurst, J. (2017). The politics of evidence: From evidence-based policy to the good governance of evidence. New York, NY: Routledge.

Pfitzner, R., Garas, A., Schweitzer, F. (2012). Emotional divergence influences information spreading in Twitter. Proceedings of ICWSM-12 $6^{\text {th }}$ International AAAI Conference on Weblogs and Social Media (pp. 543-546). Palo Alto, CA: AAAI Press.

Polikoff, M. S., Hardaway, T., Marsh, J. A., \& Plank, D. N. (2016). Who is opposed to Common Core and why? Educational Researcher, 45(4), 263-266.

Porter, R. E., Fusarelli, L. D., \& Fusarelli, B. C. (2014). Implementing the Common Core: How educators interpret curriculum reform. Educational Policy, 29(1), 111-139.

Poschko, J. (2011). Exploring Twitter hashtags. Retrieved from http://arxiv.org/abs/1111.6553

Preethi, P. G., \& Ajit kumar, V. U. (2015). Temporal sentiment analysis and causal rules extraction from Tweets for event prediction. Procedia Computer Science, 48, 84-89.

Prpić, J., Taeihagh, A., \& Melton, J. (2015). The fundamentals of policy crowdsourcing. Policy and Internet, 7(3), 340-361.

Radzikowski, J., Stefanidis, A., Jacobsen, K. H., Croitoru, A., Crooks, A., \& Delamater, P. (2016). The measles vaccination narrative in Twitter: A quantitative analysis. JMIR Public Health and Surveillance, 2(1), e(1). doi: 10.2196/publichealth.5059 
Ram, S., Zhang, W., Williams, M., \& Pengetnze Y. (2015). Predicting asthma-related emergency department visits using Big Data. IEEE Journal of Biomedical and Health Informatics, 19(4), 1216-1223.

Reddicka, C. G., Chatfieldb, A. T., \& Jaramilloa, P. A. (2015). Public opinion on National Security Agency surveillance programs: A multi-method approach. Government Information Quarterly, 32(2), 129-141.

Rogers, E. (2003). Diffusion of innovation ( $5^{\text {th }}$ ed.). New York, NY: Free Press.

Rogers, R. (2015). Making public policy: The new philanthropists and American education. American Journal of Economics and Sociology, 74(4), 743-774.

Schattschneider, E. E. (1935). Politics, pressure, and the tariff: A study of free private enterprise in pressure politics, as shown in the 1929-1930. New York: Prentice-Hall.

Sen, P., Dasgupta, S., Chatterjee, A., Sreeram, P. A., Mukherjee, G., \& Manna, S. S. (2002). Small world properties of the Indian rail network. Physical Review E, 67, 036106. doi: 10.1103/PhysRevE.67.036106

Shah, D. V., Cappella, J. N., \& Neuman, W. R. (2015). Big data, digital media, and computational social science: Possibilities and perils. The Annals of the American Academy of Political and Social Science, 659(1), 6-13.

Shavelson, R. J. (1988). Contributions of educational research to policy and practice: Constructing, challenging, changing cognition. Educational Researcher, 17(7), 4-11.

Siqi, Z., Lin, Z., Jehan, W., \& Venu, V. (2011). Human as real-time sensors of social and physical events: A case study of Twitter and sports games. arXiv:1106.4300 [cs.SI]. Retrieved from http://arxiv.org/abs/1106.4300 
Stephen, B. (2015). Social media helps Black Lives Matter fight the power. Wired. Retrieved from http://www.wired.com/2015/10/how-black-lives-matter-uses-social-media-to-fightthe-power/

Stieglitz, S., \& Dang-xuan, L. (2013). Emotions and information diffusion in social mediasentiment analysis of Microblogs and sharing behavior. Journal of Management Information Systems, 29(4), 217-247.

Song, M., \& Miskel, C. G. (2005). Who are the influentials? A cross-state social network analysis of the reading policy domain. Educational Administration Quarterly, 41(1), 748.

Supovitz, J. A., Daly, A. J., \& Del Fresno, M. (2015, February 23). \#CommonCore: How social media is changing the politics of education. Consortium for Policy Research in Education. Retrieved from http://repository.upenn.edu/hashtagcommoncore/1

Supovitz, J. A., \& Reinkordt, E. (2017). Keep your eye on the metaphor: The framing of the Common Core on Twitter. Education Policy Analysis Archives, 25(31), 1-29. doi: http://dx.doi.org/10.14507/epaa.25.2285

Thelwall, M., Buckley, K., Paltoglou, G., Cai, D., \& Kappas, A. (2010). Sentiment strength detection in short informal text. Journal of the American Society for Information Science and Technology, 61(12), 2544-2558.

Twitter. (2016). REST APIs. Retrieved from https://dev.twitter.com/rest/public Ujifusa, A. (2013, February 6). Pressure mounts in some states against the Common Core. Education Week. Retrieved from http://www.edweek.org/ew/articles/2013/02/06/20commoncore_ep.h32.html 
Vaccari, C. (2012). From echo chamber to persuasive device? Rethinking the role of the Internet in campaigns. New Media \& Society, 15(1), 109-27.

Valant, J., \& Newark, D. A. (2016). The politics of achievement gaps: U.S. public opinion on race-based and wealth-based differences in test scores. Educational Researcher, 45(6), 311-346.

Virginia’s Legislative Information System. (2015). HB 1752 SOL; Bd. of Education prohibited from adopting revisions that implement Common Core State Standards. Retrieved from https://lis.virginia.gov/cgi-bin/legp604.exe?151+sum+HB1752

Wallsten, P., \& Layton, L. (2013, May 30). Tea party groups rallying against Common Core education overhaul. The Washington Post. Retrieved from https://www.washingtonpost.com/politics/tea-party-groups-rallying-against-commoncore-education-overhaul/2013/05/30/64faab62-c917-11e2-9245773c0123c027_story.html

Wang, Y. (2016a). Getting personal! Twitter communication between school districts, superintendents, and the public. Journal of School Leadership, 26(5), 865-890.

Wang, Y. (2016b). U.S. State education agencies' use of Twitter: Mission accomplished? Sage Open, 6(1), 1-12.

Wang, Y., \& Bowers, A. J. (2016). Mapping the field of educational administration research: A journal citation network analysis. Journal of Educational Administration, 54(3), 242-269.

Wang, Y., Sauers, N., \& Richardson, J. (2016). A social network approach to examine K-12 educational leaders' influence on information diffusion on Twitter. Journal of School Leadership, 26(3), 495-522.

Wasserman, S., \& Faust, K. (1994). Social network analysis: Methods and applications. New 
York, NY: Cambridge University Press.

Watts, D. J. (2013). Computational social science: Exciting progress and future directions. The Bridge Linking Engineering and Society, 43(4), 5-11.

Weiler, A., Grossniklaus, M., \& Scholl, M. H. (2015). Run-time and task-based performance of event detection techniques for Twitter. Advanced Information Systems Engineering: Lecture Notes in Computer Science, 9097, 35-49.

Whitman, W. N. (2015). Trending now: Using big data to examine public opinion of space policy. Space Policy, 32, 11-16.

Widener, M. J., \& Li, W. (2014). Using geolocated Twitter data to monitor the prevalence of healthy and unhealthy food references across the US. Applied Geography, 54, 189-197.

Williams, S. A., Terras, M. M., \& Warwick, C. (2013). What do people study when they study Twitter? Classifying Twitter related academic papers. Journal of Documentation, 69(3), $383-410$.

Witherspoon, C. L., \& Stone, D. N. (2013). Analysis and sentiment detection in online reviews of tax professionals: A comparison of three software packages. Journal of Emerging Technologies in Accounting, 10(1), 89-115.

Witteman, H. O., Fagerlin, A., Exe, N., Trottier, M., \& Zikmund-Fisher, B. (2016). One-sided social media comments influenced opinions and intentions about home birth: An experimental study. Health Affairs, 35(4), 726-733.

Wohlstetter, P., Houston, D. M., \& Buck, B. (2014). Networks in New York City: Implementing the Common Core. Educational Policy, 29(1), 85-110.

Yi, J., Nasukawa, T., Bunescu, R., \& Niblack, W. (2003). Sentiment analyzer: Extracting sentiment about a given topic using natural language processing techniques. Proceedings 
of the Third IEEE International Conference on Data Mining, New York, NY: IEEE. doi: 10.1109/ICDM.2003.1250949

Young, S. D., Rivers, C., \& Lewis, B. (2014). Methods of using real-time social media technologies for detection and remote monitoring of HIV outcomes. Preventive Medicine, $63,112-115$.

Yuen, T. T., \& Pickering, T. A. (2015, 9-12 April). Investigation of social networks and discussions in STEM education communities on Twitter. Paper presented at the 2015 International Conference on Learning and Teaching in Computing and Engineering (pp. 128-133), Taipei, China. Institute of Electrical and Electronics Engineers. doi: 10.1109/LaTiCE.2015.20

Zernike, K. (2015, November 21). Massachusetts's rejection of Common Core test signals shift in U.S. New York Times. Retrieved from http://www.nytimes.com/2015/11/22/us/rejecting-test-massachusetts-shifts-itsmodel.html?_r=1 


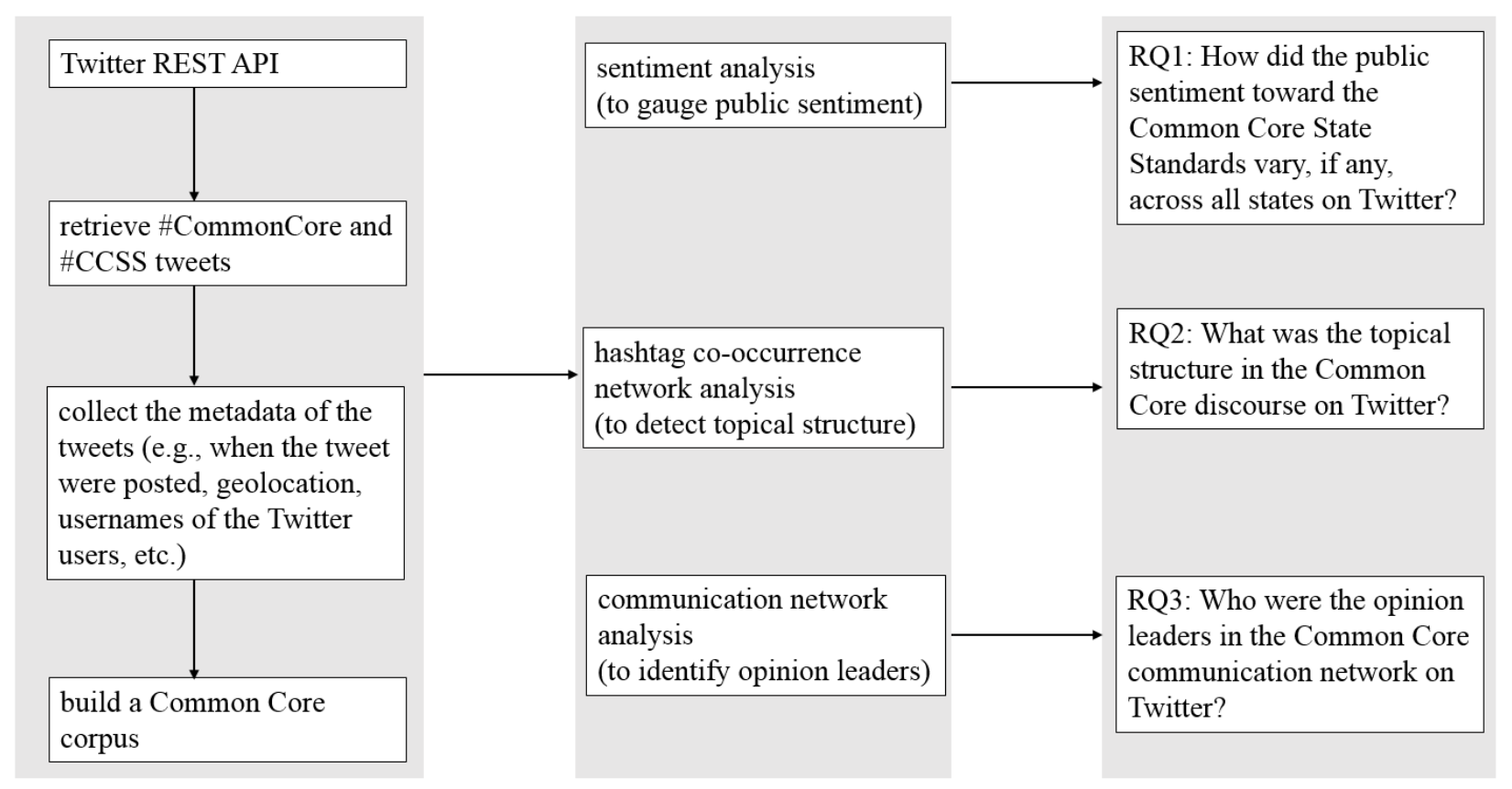

Figure 1 Overview of research design.

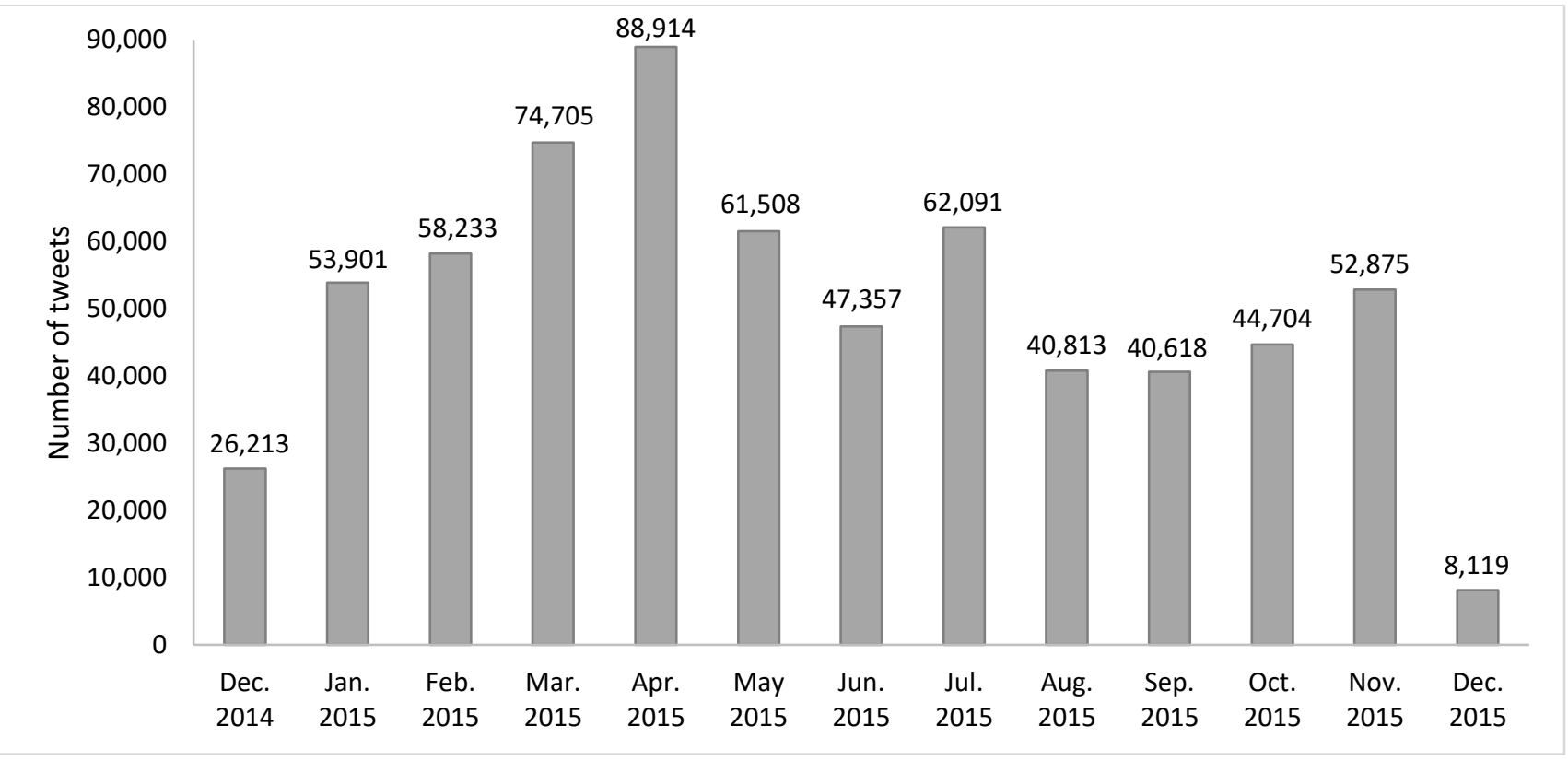

Figure 2 The tweets containing the hashtags \#CommonCore and \#CCSS by month. 


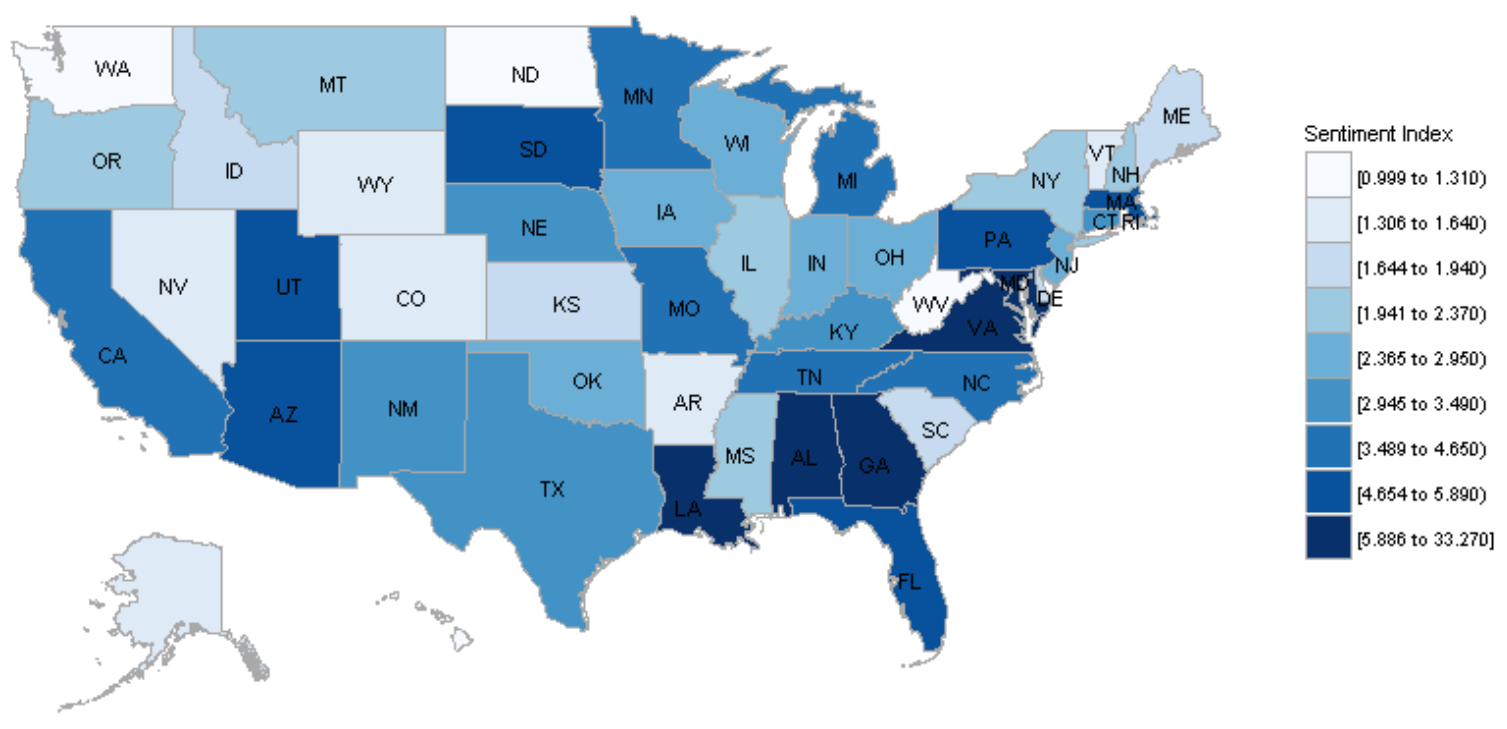

Figure 3 Choropleth map of Sentiment Indexes on the Common Core. A darker shade of color suggests the Twitter users from the state expressed more negative sentiment towards the Common Core on Twitter.

Table 1 The States' Common Core Sentiment Index by the Extent of Common Core Adoption

\begin{tabular}{|c|c|c|c|c|c|c|}
\hline \multirow{2}{*}{ Adoption phase } & \multirow{2}{*}{ Number of states } & \multicolumn{5}{|c|}{ Sentiment Index } \\
\hline & & Min. & Max. & Mean & Median & $S D$ \\
\hline 1-adopted verbatim & 23 & 1.00 & 6.01 & 2.42 & 1.97 & 1.33 \\
\hline 2-adopted with modification & 20 & 1.24 & 9.91 & 3.94 & 3.99 & 2.28 \\
\hline 3-partially adopted & 1 & 4.38 & 4.38 & -- & -- & -- \\
\hline 4-withdrawn & 3 & 1.69 & 2.43 & 2.06 & 2.37 & 0.41 \\
\hline 5-not adopted & 4 & 1.51 & 33.27 & 10.33 & 3.28 & 15.31 \\
\hline Total & 51 & 1.00 & 33.27 & 3.66 & 2.44 & 4.61 \\
\hline
\end{tabular}




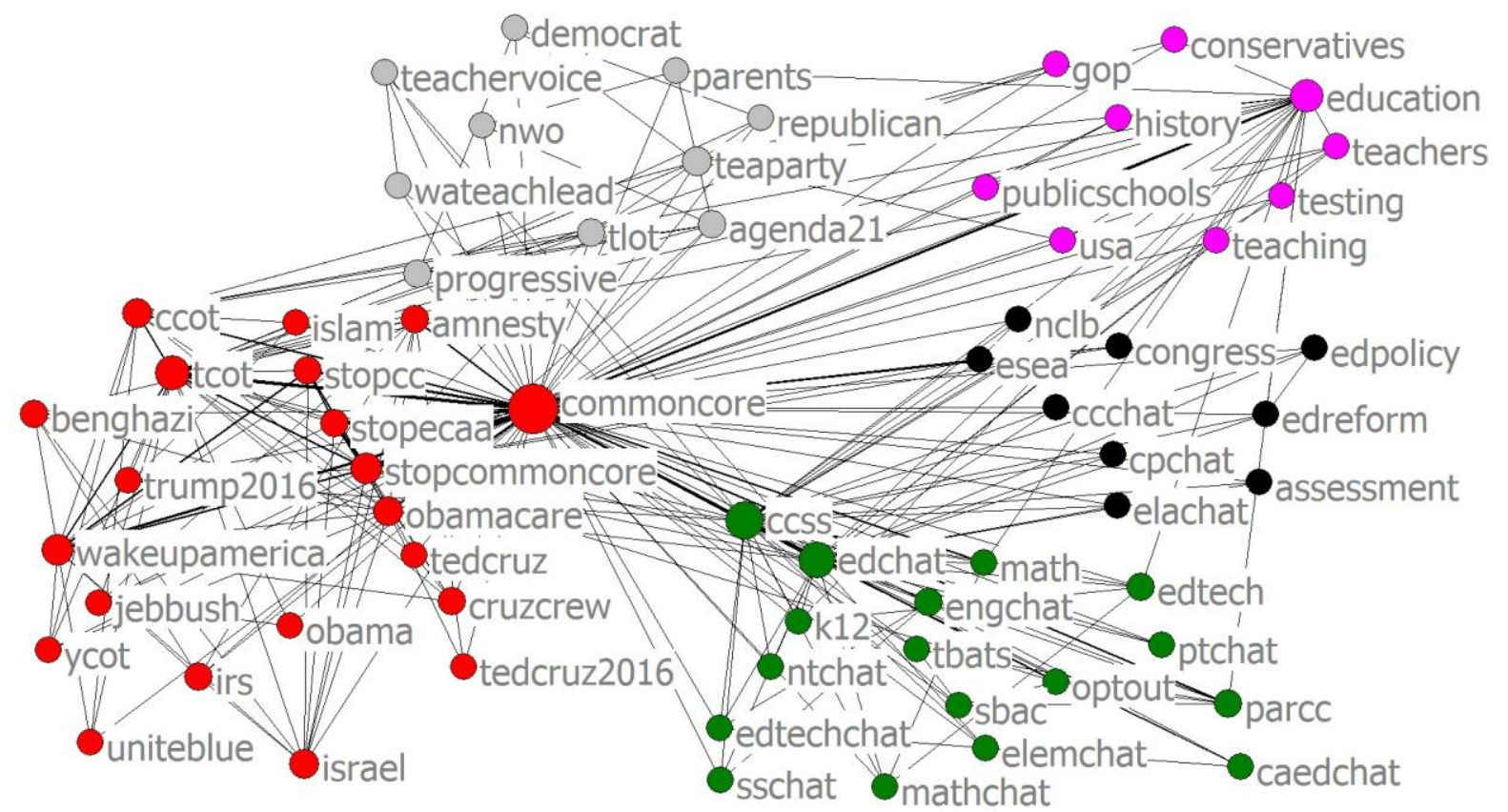

Figure 4 The Common Core hashtag co-occurrence Network (tie strength $\geq 200$ ). The network contains 66 hashtags and 249 co-occurrence ties. Node size represents degree, and node color represents the nodes in different clusters.

Table 2 High-centrality Twitter Users and Their Sentiment towards the Common Core

\begin{tabular}{clllll}
\hline Rank & Indegree & In-Bonacich Power & Betweenness & Outdegree & Out-Bonacich Power \\
\hline 1 & User1 & User1 & User1 & User1 & User11 \\
2 & User2 & User11 & User3 & User26 & User1 \\
3 & User3 & User12 & User17 & User27 & User31 \\
4 & User4 & User13 & User20 & User4 & User32 \\
5 & User5 & User14 & User4 & User28 & User33 \\
6 & User6 & User15 & User21 & User29 & User26 \\
7 & User7 & User16 & User22 & User7 & User27 \\
8 & User8 & User17 & User23 & User10 & User3 \\
9 & User9 & User18 & User24 & User30 & User20 \\
10 & User10 & User19 & User25 & User3 & User34 \\
\hline
\end{tabular}

Note: The gray cell represents that the Twitter user who expressed negative sentiment towards the Common Core; white represents neutral sentiment. 